\title{
Rechtsschutz bei überlangen Gerichtsverfahren im Lichte der Vorgaben des EGMR
}

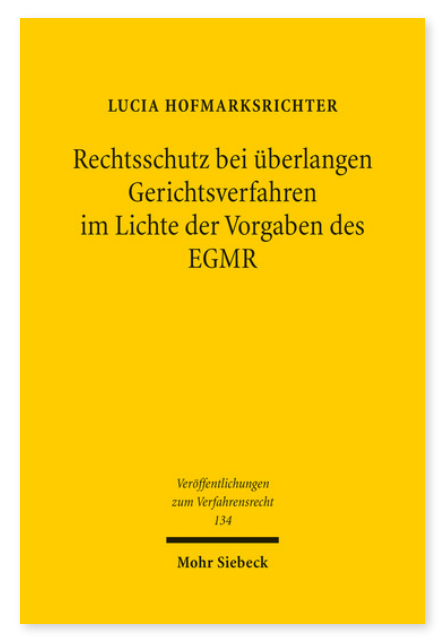

2017. XXV, 214 Seiten. VVerfR 134

ISBN 978-3-16-154988-5

DOI 10.1628/978-3-16-154988-5

eBook PDF 89,00€

ISBN 978-3-16-154835-2

fadengeheftete Broschur 89,00€
Der EGMR bemängelte vor Einführung der §§ 198 ff. GVG, dass es in Deutschland keinen Rechtsschutz gäbe, mit dem die überlange Dauer eines Verfahrens im Einzelfall wirksam gerügt werden könne. Lucia Hofmarksrichter stellt den Rechtsschutz nach §§ 198 ff. GVG dar und wertet die Vorgaben des EGMR nach Art. 13 EMRK und Art. 6 Abs. 1 EMRK aus. Die Effektivitätsvorgaben erläutert sie im Hinblick auf die Anforderungen für deutsche Zivilprozesse und unterzieht sie einer wertenden Betrachtung im normenhierarchischen Mehrebenensystem zwischen Grundgesetz und EMRK. Zudem entwickelt sie konkrete Vorschläge zur Auflösung des im Einzelfall bestehenden Interessenkonflikts zwischen dem Recht auf angemessene Verfahrensdauer und den übrigen zivilprozessualen Verfahrensmaximen und insbesondere dem Recht auf richterliche Unabhängigkeit. Die Autorin kommt zu dem Ergebnis, dass der Rechtsschutz nach §§198 ff. GVG aktuell nur teilweise mit den Vorgaben des EGMR übereinstimmt. Zur vollständigen Umsetzung der Vorgaben des EGMR unterbreitet sie einen eigenen Gesetzesvorschlag.

Die Arbeit wurde mit dem Juratisbona-Preis für herausragende Doktorarbeiten 2016 der Universität Regensburg ausgezeichnet.

Lucia Hofmarksrichter Geboren 1983; Studium der Rechtswissenschaften in München; Rechtsreferendariat am Oberlandesgericht München; 2011 Zweites Staatsexamen; Rechtsanwältin im Bereich Prozessführung und Schiedsverfahren in München.
Jetzt bestellen:

https://mohrsiebeck.com/buch/rechtsschutz-bei-ueberlangen-gerichtsverfahren-im-lichte-der-vorgaben-des-egmr-

9783161549885?no_cache=1

order@mohrsiebeck.com

Telefon: +49 (0)7071-923-17

Telefax: +49 (0)7071-51104 